\title{
Reconstrução da cápsula superior com Aloenxerto de fáscia lata para Roturas irreparáveis do tendão do músculo supraespinal*
}

\section{Superior Capsular Reconstruction with Fascia Lata Allograft for Irreparable Supraspinatus Tendon Tears}

\author{
Mauro Emilio Conforto Gracitelli ${ }^{1}$ Rodrigo Alves Beraldo ${ }^{1} \quad$ Eduardo Angeli Malavolta ${ }^{1}$ \\ Jorge Henrique Assunção ${ }^{1}$ Danilo Ricardo Okiishi de Oliveira ${ }^{1}$ Arnaldo Amado Ferreira Neto ${ }^{1}$
}

\footnotetext{
1 Instituto de Ortopedia e Traumatologia, Faculdade de Medicina da Universidade de São Paulo (HCFMUSP), São Paulo, SP, Brasil

Endereço para correspondência Mauro Emilio Conforto Gracitelli, Instituto de Ortopedia e Traumatologia, Faculdade de Medicina da Universidade de São Paulo (HCFMUSP), São Paulo, SP, Brasil Rev Bras Ortop 2019;54:591-596. (e-mail: mgracitelli@gmail.com).
}

\section{Resumo \\ Palavras-chave \\ - ombro \\ - lesões do manguito rotador \\ - artropatia do manguito rotador \\ - músculo supraespinal}

A reconstrução da cápsula superior é um procedimento descrito recentemente para o tratamento das roturas irreparáveis do tendão do músculo supraespinal. Como opções de enxerto podemos citar o uso de fáscia lata autógena e enxerto dermal acelularizado. Nenhum estudo foi publicado com o uso de aloenxerto de fáscia lata. O objetivo desta nota é descrever a técnica cirúrgica da reconstrução da cápsula superior com aloenxerto de fáscia lata. O procedimento é feito por visão artroscópica, com o paciente posicionado em decúbito lateral. Os autores descrevem uma técnica baseada no uso do nó em dupla polia na glenoide e no tubérculo maior, que facilita o procedimento e permite que o enxerto seja levado para o espaço subacromial na posição definitiva e com a tensão adequada. Os aloenxertos usados são provenientes de banco de tecidos, onde são criopreservados e submetidos à avaliação microbiológica e histopatológica. A reconstrução da cápsula superior é uma cirurgia promissora. A técnica descrita mostra uma opção artroscópica viável, com uso de menor número de âncoras quando comparada com as demais descrições.

\begin{abstract}
Superior capsular reconstruction is a recently described procedure for the treatment of irreparable supraspinatus tendon tears. Graft options that have been previously described include autogenous fascia lata and decellularized dermal graft. No studies were published with the use of fascia lata allograft. The purpose of this technical note is to describe the surgical technique of superior capsular reconstruction using fascia lata allograft. The procedure is performed by arthroscopy, with the patient positioned in
\end{abstract}

\footnotetext{
Trabalho desenvolvido no Grupo de Ombro e Cotovelo, Instituto de Ortopedia e Traumatologia, Hospital das Clínicas, Faculdade de Medicina, Universidade de São Paulo, São Paulo, SP, Brasil. Publicado Originalmente por Elsevier Editora Ltda.
}

recebido

06 de Setembro de 2017

aceito

07 de Novembro de 2017
DOI https://doi.org/ 10.1016/j.rbo.2017.11.011. ISSN 0102-3616.
Copyright $\odot 2019$ by Sociedade Brasileira License terms de Ortopedia e Traumatologia. Published by Thieme Revnter Publicações Ltda, Rio de Janeiro, Brazil 
Keywords

- shoulder

- rotator cuff tear

- rotator cuff arthropathy

- supraspinatus tendon the lateral decubitus position. The authors describe a technique based on the use of a double-pulley knot in the glenoid and the greater tuberosity, facilitating the procedure and allowing the graft to be brought into the subacromial space in the definitive position, with the appropriate tension. The allografts are available from this institution's tissue bank, cryopreserved and submitted to microbiological and histopathological evaluation. Superior capsular reconstruction is a promising surgery. The technique described in the present technical note shows a viable arthroscopic alternative, with a smaller number of anchors when compared to the other techniques.

\section{Introdução}

A reconstrução da cápsula superior é um procedimento descrito recentemente para o tratamento das roturas irreparáveis do tendão do músculo supraespinal. ${ }^{1,2} \mathrm{O}$ procedimento tem como objetivo restaurar a estabilidade superior da articulação glenoumeral e, assim, melhorar a elevação do ombro. ${ }^{2}$ É uma técnica feita por visão artroscópica, com baixa morbidade e riscos quando comparada com as outras opções cirúrgicas, como artroplastia reversa e transferências musculares. ${ }^{1}$ Estudos biomecânicos e clínicos demonstraram a eficácia do procedimento para a melhoria funcional, além de demonstrar alta taxa de cicatrização do enxerto no úmero e na glenoide. ${ }^{1,3-5}$ As indicações do procedimento ainda são controversas, sendo que melhores resultados foram observados em pacientes sintomáticos com rotura irreparável do tendão do músculo supraespinal, associada ou não a roturas pequenas do subscapular e coma presença de rotação lateral ativa. É descrito também em casos de artropatia do manguito rotador em graus iniciais. ${ }^{1,3}$

Como opções de enxerto, podemos citar o uso da fáscia lata autóloga, ${ }^{5}$ que apesar de ser um procedimento seguro apresenta a desvantagem de acrescentar maior morbidade ao paciente. A derme humana acelularizada também tem sido usada, ${ }^{6}$ mas apresenta as desvantagens de ser menos resistente, não estar disponível em nosso meio, e aumentar de maneira significativa o custo do procedimento.,

O objetivo desta nota é descrever a técnica cirúrgica da reconstrução da cápsula superior com âncoras convencionais e aloenxerto de fáscia lata.

\section{Descrição da Técnica}

\section{Anestesia e posicionamento}

Cirurgia feita sob anestesia geral e bloqueio do plexo braquial. 0 paciente é posicionado em decúbito lateral com o membro superior abduzido a um ângulo de $45 \circ$ com, e com tração cutânea.

\section{Portais}

Os portais tradicionais para reparo do manguito rotador são feitos, e consistem no portal posterior (PP), anterior (PA) e lateral (PL). O PA é feito $1,5 \mathrm{~cm}$ superior à extremidade distal do coracoide e permite a colocação da âncora anterior na glenóide. O PL é feito $2,5 \mathrm{~cm}$ inferior ao acrômio. Por esse portal será inserido o enxerto, sendo essencial a bursectomia adja- cente ao deltoide. São feitos mais dois portais para a inserção das âncoras no tubérculo maior, anterossuperior (AS) e posterossuperior (PS). Também é feito o portal de Neviaser (PN) na bissetriz entre a interseção da clavícula e a espinha da escápula. Esse portal permite a inserção da âncora posterior na glenoide e permite a tração do enxerto por um sistema de dupla polia. Eventualmente, pode ser necessário um portal posterossuperior medial (PPSM), $3 \mathrm{~cm}$ medial e $1 \mathrm{~cm}$ inferior ao ângulo posterolateral do acrômio, para a inserção da âncora posterior da glenóide, nos casos em que o PNnão permite um ângulo de ataque adequado. Para o reparo do subescapular, pode ser necessário um portal adicional anterolateral.

Realizamos o procedimento com três cânulas. Duas cânulas rígidas tradicionais são usadas no PA e no PP. Uma terceira cânula, flexível, Passport (Arthrex, Naples, FL, EUA), é usada no PL. Essa cânula permite a passagem dos fioss sem interposição de partes moles entre eles. Ela será cortada e retirada após a passagem de todos os fios para permitir a entrada do enxerto no espaço subacromial. Na indisponibilidade desse modelo, realizamos sem cânula, mas com precaução para evitar a interposição de partes moles no PL, buscando sempre visualizar a passagem dos fios pelo mesmo orifício no deltoide.

\section{Preparo}

É feita uma inspeção articular e subacromial completa. Roturas completas ou parciais superiores a $5 \mathrm{~mm}$ do subescapular são reparadas. Após o término do inventário articular, é abordado o espaço subacromial e feita a bursectomia ampla. $O$ tendão da cabeça longa do bíceps é abordado quando apresentar subluxação ou luxação, lesões parciais superiores a $50 \%$, ou na existência de lesões do lábio superior dos tipos 2, 3, e 4, de acordo com a classificação de Snyder. Caso seja confirmada a irreparabilidade do tendão do músculo supraespinal, o procedimento de reconstrução da cápsula superior será iniciado.

O tubérculo maior é desbridado até estar livre de cotos tendíneos e tecido bursal, apresentando bom leito para o enxerto. A porção superior da glenoide é desbridada, até a espinha da escápula posteriormente e até a base do coracoide anteriormente. $O$ colo superior da glenoide é preparado até um leito sangrante ser obtido. Deve-se evitar o preparo além de $1,5 \mathrm{~cm}$ medial à superfície articular da glenoide para evitar danos ao nervo supraescapular. A base do coracoide deve ser visualizada e preparada, pois a âncora anterior deverá ser inserida imediatamente lateral ao coracoide. 


\section{Âncoras}

Após o preparo, as âncoras deverão ser inseridas nos locais planejados. Para o procedimento de reconstrução da cápsula superior com fileira simples, são usadas, no mínimo, quatro âncoras. A preferência é pelas âncoras absorvíveis, duplamente carregadas com fios da alta resistência. No entanto, âncoras metálicas também podem ser usadas, tanto na glenóide quanto no tubérculo maior. A potencial desvantagem está relacionada à revisão do procedimento para uma artroplastia reversa. Nessa mesma técnica podem ser adicionadas âncoras laterais no tubérculo para a fixação em fileira dupla, o que aumenta a resistência mecânica da reconstrução.

As âncoras da glenoide são inseridas inicialmente, com visualização pelo PL. A âncora anterior é inserida pelo PA, que deve permitir um ângulo de ataque adequado logo lateral à base do coracoide, cerca de $1 \mathrm{~cm}$ medial à superfície articular da glenoide. A âncora posterior pode ser inserida pelo PN, dista cerca de $2 \mathrm{~cm}$ da âncora anterior.

As âncoras do tubérculo maior serão inseridas pelos portais acessórios AS e PS. Na técnica de fileira simples, âncoras são inseridas cerca de $1 \mathrm{~cm}$ lateral à borda articular da cabeça do úmero.

Mensuração das distâncias entre os pontos de fixação As distâncias entre as quatro âncoras são mensuradas a seguir, conforme demonstrado na - Figura 1. Existem medidores específicos para esse fim, mas fizemos essas medidas com um fio inabsorvível e pinças tipo grasper. A distância entre as âncoras da glenoide e do tubérculo é que permitirá a tensão adequada do enxerto e deve ser feita de modo cuidadoso e com o ombro estático e em 45 。 de abdução.

\section{Preparo do Aloenxerto de fáscia lata}

Os aloenxertos usados são provenientes do banco de tecidos de nosso serviço. A obtenção dos aloenxertos tem como doadores indivíduos falecidos com morte encefálica, após um rigoroso controle sorológico e processamento mecânico. Os tecidos são imersos em soluções emulsificantes à base de peróxido de hidrogênio e álcool, sob agitação ultrassônica, e amostras de fragmentos são submetidas à avaliação microbiológica e histopatológica. É feita a embalagem em invólucros triplos estéreis, selados a vácuo e devidamente identificados. Os tecidos são armazenados em salas de criopreservação (entre -85 e $-110 \circ \mathrm{C}$ ), por um período máximo de 5 anos. 0 preparo do enxerto de fáscia lata é feito por um auxiliar logo após a determinação da irreparabilidade do tendão do músculo supraespinal. Fizemos o preparo do enxerto em um tamanho padrão, com $4 \mathrm{~cm}$ de largura e $5,5 \mathrm{~cm}$ de comprimento, dobrado 4 vezes sobre si. A espessura obtida varia entre 4 a $6 \mathrm{~mm}$. São feitas suturas simples ao redor de todas as bordas do enxerto, com fio inabsorvível 2-0. Suturas adicionais entre as camadas, no centro do enxerto, são feitas para evitar seu deslizamento.

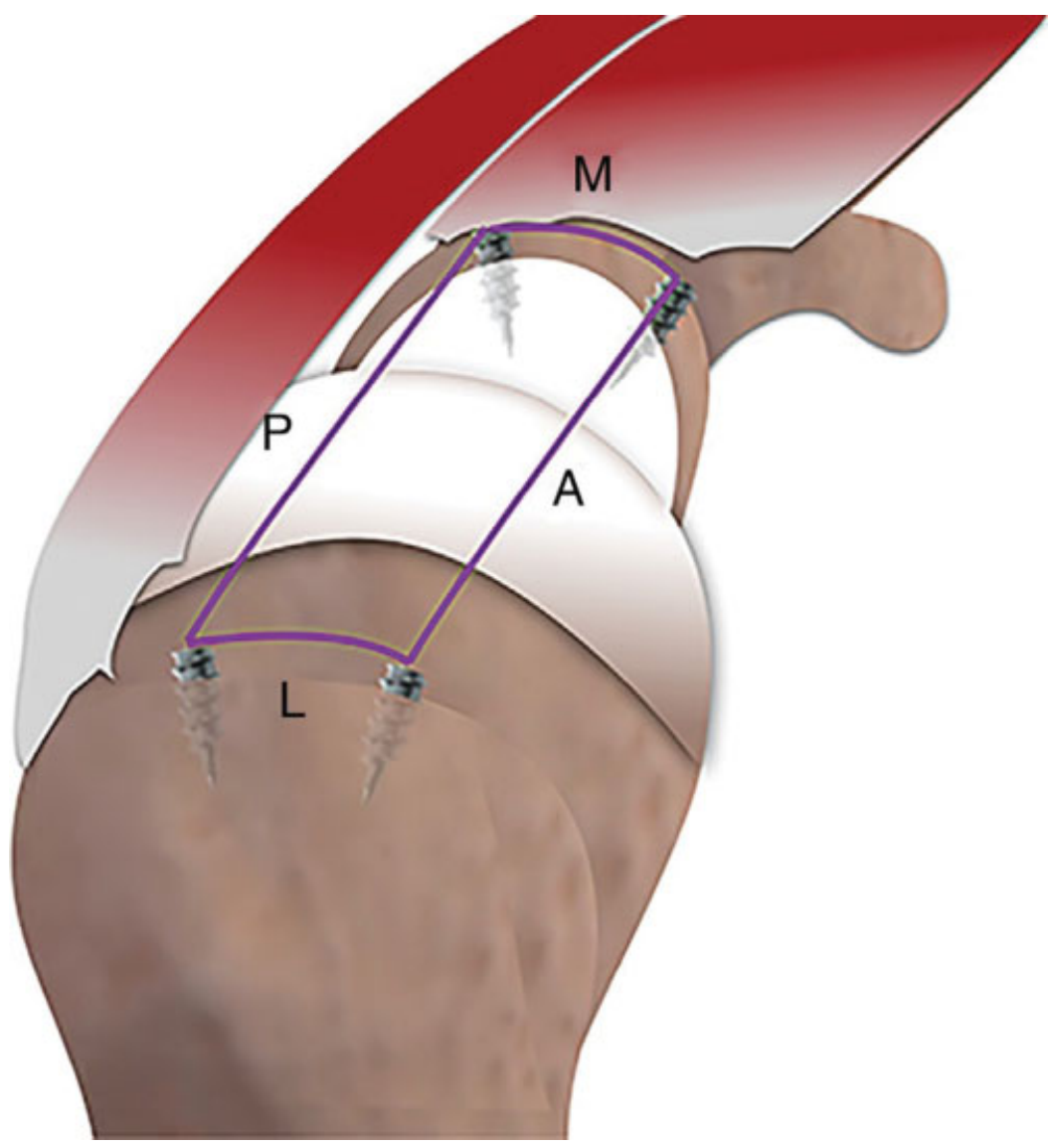

Fig. 1 Medidas das distâncias entre as âncoras anteriores e posteriores da glenoide (medida M) e do tubérculo maior (medida L), e a distância entre as âncoras da glenoide e tubérculo maior anteriores (medida A) e posteriores (medida P). 
As medidas descritas acima previamente são usadas para determinar o local da passagem dos pontos no enxerto. Também são passados dois fios inabsorvíveis na borda posterior do enxerto para o reparo do tendão do infraespinal no enxerto, presos com um nó espesso, que impede o seu escorregamento. $\mathrm{O}$ aspecto final do enxerto e dos fios é demonstrado na - Figura 2.

\section{Manejo dos fios e passagem do enxerto}

A etapa mais complexa do procedimento reside no manejo dos fios de sutura e na passagem dos fios no enxerto. Descrevemos nossa técnica na - Figura 3.

A sutura é baseada no uso do nó em dupla polia na glenoide e no tubérculo maior, permitindo que o enxerto seja levado para o espaço subacromial na posição definitiva e com a tensão adequada.

\section{Seguimento pós-operatório}

Após o procedimento cirúrgico, os pacientes são imobilizados com tipoia com almofada abdominal por seis semanas. A reabilitação segue o mesmo protocolo de um reparo de rotura extensa do manguito rotador. Os pacientes são orientados a fazer movimentação passiva do ombro após 4 semanas e ativa após 6 semanas. Doze semanas após a cirurgia, os pacientes começam a fazer exercícios para fortalecer o manguito rotador remanescente e a musculatura estabilizadora da escápula.

\section{Comentários finais}

A reconstrução da cápsula superior é uma técnica promissora para uma situação clínica sem padrão-ouro de tratamento. Essa descrição da técnica, baseada em nossa experiência inicial em uma coorte prospectiva em

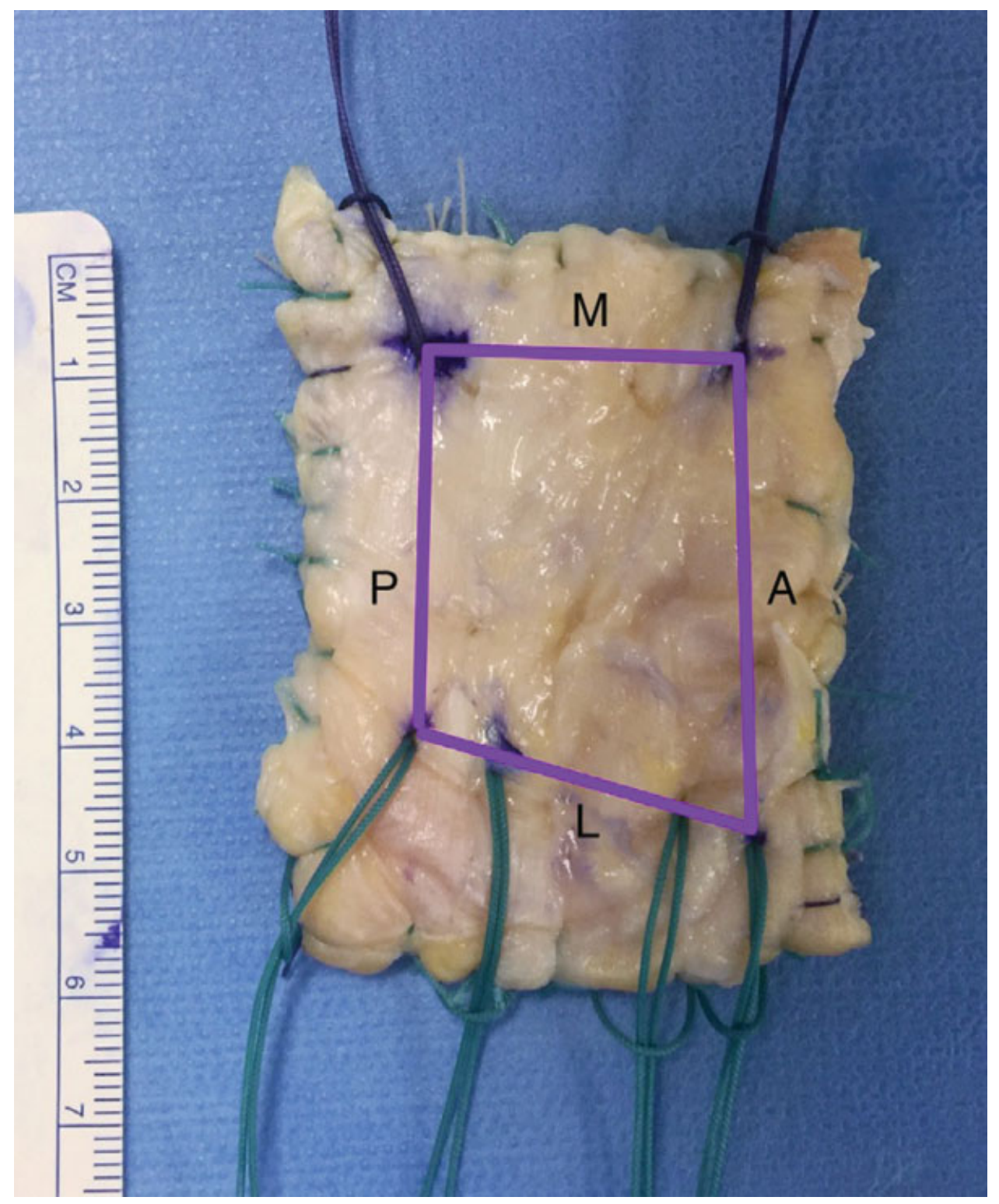

Fig. 2 Fios provisórios inseridos nos locais previamente mensurados, com coloração diferente para a porção lateral (verde) e medial (roxo) do enxerto. Abreviaturas: A, anterior; P, posterior; M, medial; L, lateral. 


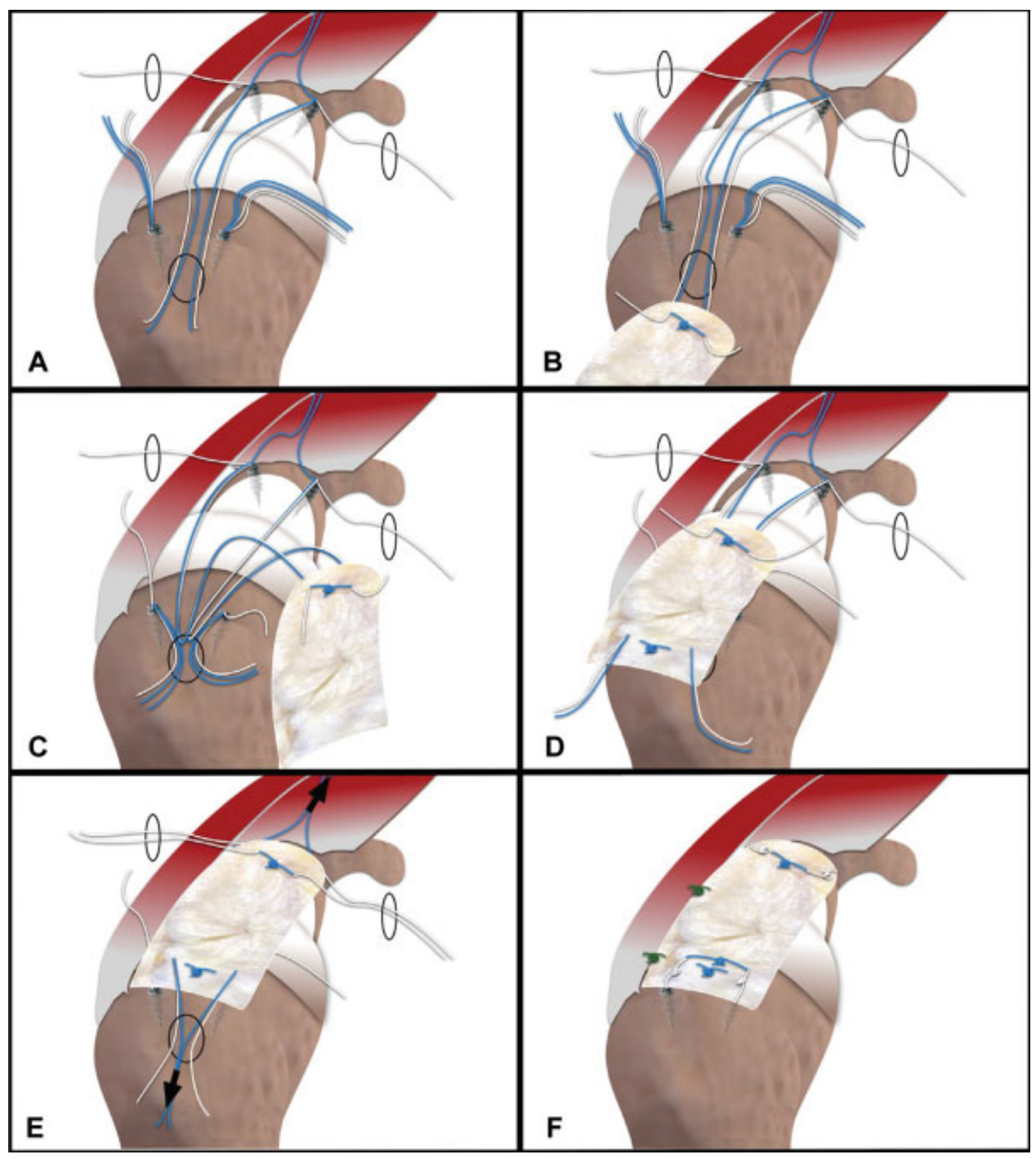

Fig. 3 Descrição detalhada da sutura do enxerto. (A). Os fios das âncoras da glenoide são passados para os portais demonstrados; (B). Os fios (brancos e azuis) são suturados na borda medial do enxerto. Os dois fios azuis (um de cada âncora da glenoide) serão suturados entre si, criam uma polia dupla; (C). Com o enxerto externo ao ombro, três fios de cada âncora do tubérculo (dois azuis e um branco) são passados para o portal lateral; (D). Um fio de cada cor da âncora anterior e posterior do tubérculo é passado no local previamente demarcado (distância L). A seguir, os fios azuis remanescentes são suturados, formando uma polia dupla lateral; (E). Os fios azuis do portal de Neviaser são tracionados nesse momento e o enxerto é empurrado para o espaço subacromial com o auxílio de uma pinça. A seguir, os fios da polia dupla lateral são tracionados e o enxerto estará provisoriamente fixo. (F). Os fios brancos mediais e laterais são suturados com nós deslizantes, antes dos fios azuis das polias duplas. A seguir, os fios azuis são suturados com nós não deslizantes. No fim, dois ou mais pontos são feitos entre o enxerto e o infraespinal.

andamento, descreve em detalhes uma opção artroscópica viável e reprodutível e que tem apresentado bons resultados clínicos. Além disso, é o primeiro estudo de reconstrução da cápsula superior a descrever o uso do aloenxerto de fáscia lata, disponível em centros nacionais de banco de tecidos, o que evita a morbidade do sítio doador. Para os serviços que não têm a disponibilidade de banco de tecidos, a mesma técnica de sutura descrita neste artigo pode ser aplicada com o uso de autoenxerto da fáscia lata, conforme descrito inicialmente por Mihata et al., 1,4 apesar de aumentar a morbidade e o tempo cirúrgico do procedimento.

Apesar da descrição de bons resultados funcionais, ${ }^{1,3}$ futuros estudos clínicos são necessários para determinar a eficácia desse método em longo prazo, as taxas de cicatri- zação da cápsula reconstruída e a sua comparação com métodos tradicionais, como o reparo parcial do manguito rotador.

Conflitos de Interesse

Os autores declaram não haver conflitos de interesse.

\section{Referências}

1 Mihata T, Lee TQ Watanabe C, et al. Clinical results of arthroscopic superior capsule reconstruction for irreparable rotator cuff tears. Arthroscopy 2013;29(03):459-470

2 Mihata T, McGarry MH, Pirolo JM, Kinoshita M, Lee TQ. Superior capsule reconstruction to restore superior stability in irreparable rotator cuff tears: a biomechanical cadaveric study. Am J Sports Med 2012;40(10):2248-2255 
596 Reconstrução da Cápsula Superior com Aloenxerto de Fáscia Lata Gracitelli et al.

3 Mihata T, Lee TQ Itami Y, Fujisawa Y, Ohue M, Neo M. Arthroscopic superior capsule reconstruction for irreparable rotator cuff tears: a prospective clinical study in 100 consecutive patients with 1 to 8 years of follow-up. J Shoulder Elbow Surg 2016;25(06): e188-90 (Paper \#41).

4 Mihata T, McGarry MH, Kahn T, Goldberg I, Neo M, Lee TQ. Biomechanical effect of thickness and tension of fascia lata graft on glenohumeral stability for superior capsule reconstruction in irreparable supraspinatus tears. Arthroscopy 2016;32(03):418-426
5 Mihata T, McGarry MH, Kahn T, Goldberg I, Neo M, Lee TQ. Biomechanical role of capsular continuity in superior capsule reconstruction for irreparable tears of the supraspinatus tendon. Am J Sports Med 2016;44(06):1423-1430

6 Tokish JM, Beicker C. Superior capsule reconstruction technique using an acellular dermal allograft. Arthrosc Tech 2015;4(06):e833-e839

7 Adams CR, Denard PJ, Brady PC, Hartzler RU, Burkhart SS. The arthroscopic superior capsular reconstruction. Am J Orthop 2016; 45(05):320-324 